\title{
Anthelmintic activity of seed extracts of Artocarpusheterophyllus
}

\author{
Yashaswini.T $^{1 *}$, Akshara ${ }^{1}$, A.M.Krupanidhi ${ }^{2}$, Prasad K ${ }^{3}$, Kumar M.D $^{4}$, \\ Akshaykumar $\mathrm{K}^{5}$ \\ ${ }^{1 * 3,5}$ Department of Pharmacology, National College of Pharmacy, BalarajUrs Road, Shivamogga-577201, \\ Karnataka, India. \\ ${ }^{1,2}$ Department ofResearch Pharmacology, Bapuji Pharmacy College, Davangere -577004, Karnataka, India. \\ ${ }^{4}$ Department of Pharmaceutical Chemistry, NES Academy of Research and Development, NES Campus, \\ Shivamogga-577201, Karnataka, India
}

\begin{abstract}
Helminthic infections are now being recognized as cause of many acute as well as chronic ill healthamong the various human beings as well as cattle's. Helminthiasis, the condition resulting from worm infestation, is one of the major prevalent diseases in the world, particularly in the tropical countries. Lack of adequate sanitary facilities and supply of pure water coupled with poverty and illiteracy are some of the factors responsible for wide spread nature of this disease in the developing countries. The present study aimed at the in-vitro evaluation of anthelmintic activity of ethanol, ethyl acetate and aqueous extracts of seeds of the plant "Artocarpusheterophyllus" in earthworms (Pheretimaposthuma). The test samples were given in the dose of $25 \mathrm{mg} / \mathrm{ml}, 50 \mathrm{mg} / \mathrm{ml}$, and $100 \mathrm{mg} / \mathrm{ml}$. The ethyl acetate extract showed more significant activity when compared to ethanol and aqueous extracts of seed. Whereas ethanol and aqueous extracts has showed moderate anthelmintic activity at prefixed time. Since detailed investigation of anthelmintic activity has not been carried out so far, present study was under taken.
\end{abstract}

Keywords: Albendazole,Anthelmintic activity, Artocarpusheterophyllus, Pheretimaposthuma, earthworms.

\section{Introduction}

More than half of the population of the world suffers from infection of one or the other and majority of cattle's suffers from worm infections. Anthelmintic drugs can be classified according to their chemical structure as well as to their action against the specific type of helminthic [1]. As per WHO, only few drugs are frequently used in the treatment of these parasite infections[2]. Helminthiasis is prevalent globally (1/3 of world's population harbours them), but is more common in developing countries with poorpersonal and environmental hygiene [3]. Anthelmintics are drugs that expel parasitic worms (helminths) from the body, by either stunning or killing those [4]. The gastro-intestinal helminthes becomes resistant to currently available anthelmintic drugs; therefore, there is a foremost problem in treatment of helminthes diseases [5]. Moreover, these drugs are unaffordable because of their high cost. These factors paved the way for herbal remedies as alternative anthelmintics. An ideal anthelmintic must have a wide margin between its toxicity to the worm and its toxic effect on the host. The drug must be effective in one dose.

Plants are used medicinally in different countries and are a source of many potent and powerful drugs [6]. Artocarpusheterophyllusis a species of tree in the Artocarpus genus of the mulberry family (Moraceae)[7]. It is a native to parts of South and South East Asia, and is believed to have originated in the south western rain forest of India, Kerala, Tamilnadu, Coastal Karnataka and Maharashtra [8]. It is reported that the seeds of Artocarpusheterophyllus is a good remedy for diuretic and constipating [9]. In view of its medicinal properties, in the present study the various solvent extracts of seeds of Artocarpusheterophyllus were screened for anthelmintic activity. The Chinese consider jackfruit pulp and seeds tonic, cooling and nutritious, and to be "useful in overcoming the influence of alcohol on the system." The seed starch is given to relieve biliousness and the roasted seeds are regarded as aphrodisiac. The ash of jackfruit leaves, burned with corn and coconut shells, is used alone or mixed with coconut oil to heal ulcers. The dried latex yields artostenone, convertible to artosterone, a compound with marked androgenic action. Mixed with vinegar, the latex promotes healing of abscesses, snakebite and glandular swellings. The root is a remedy for skin diseases and asthma. An extract of the root is taken in cases of fever and diarrhoea. The bark is made into poultices. Heated leaves are placed on wounds. The wood has a sedative property; its pith is said to produce abortion. It is reported that the medicinal value is due to the presence of some chemical substance that produces a physiological action on the Human body and therefore researchers always try to isolate these chemical substances from plants. 


\section{Materials And Methods}

2.1Collection and authentication of plant

The seeds of Artocarpusheterophylluswere collected from the local areas of Shimoga district. The materials were shade dried, powdered and stored in air tight containers. The plant was identified and authenticated by Taxonomist Dr.Rudrapa, Dean and Department of Botany S.R.N.M College, Shimoga. The herbarium of the identified plant was prepared and submitted to the Department of Pharmacognosy, National College of Pharmacy, Shimoga, karnataka, India.

\subsection{Preparation of plant extract}

\subsubsection{Hot extraction of seeds}

The dried seed powder was subjected to hot solvent extraction in a soxhlet extractor. The extraction carried by ethyl acetate and ethanol by successive method. All the three extracts were stored in refrigerator at $4^{\circ} \mathrm{C}\left[10^{\prime} 11\right]$.

\subsection{Phytochemical screening}

The extracts of seed were screened for the presence of Carbohydrates, Proteins, Amino acids, Alkaloids, Steroids, Triterpenoids, Tannins, Glycosides, Flavonoids and Saponins (As per the standard procedure)[1223].

\subsection{Worms}

Indian adult earthworms (Pheretimaposthuma) were collected from moist soil of Thunga dam. The earthworms were washed with normal saline to remove all the faecal matter and were used for the anthelmintic study. The earthworms of $3-5 \mathrm{~cm}$ in length and $0.1-0.2 \mathrm{~cm}$ in width were used for the experiment due to its anatomical and physiological resemblance with the intestinal roundworm parasites of human beings.

\subsection{Acute toxicity Studies}

Acute toxicity was evaluated on Swiss albino mice weighing between 25-30g. The fixed dose method was adopted as per OECD (Organization for Economic Co-operation and Development) Guideline No.423 of CPCSEA [24 25]. The therapeutic dose fixed was $500 \mathrm{mg} / \mathrm{kg}$ body weight i.e., $1 / 10 \mathrm{th}$ of the lethal dose.

\subsection{Anthelminthic activity of seeds of Artocarpusheterophyllus by in vitro method:}

The test samples prepared from seed extract of an ethanol, ethyl acetate and aqueous were tested for their anthelmintic activity by in vitro method. The adult Indian earthworms (Pheretimaposthuma) were used to evaluate anthelmintic activity.The animals were divided into 5 groups of 5 worms each. The worms of group I were released into a plate containing a solution of 50 sterile distilled water which served as control. The worms of group IIwere released into a plate containing Albendazole $(25 \mathrm{mg} / \mathrm{ml}, 50 \mathrm{mg} / \mathrm{ml}$, and $100 \mathrm{mg} / \mathrm{ml})$ which served as standard. The worms of group III, IV and Vwere released into the separate plates containing solution of test samples of seed extract (Ethanol, aqueous and ethyl acetate) at a dose of $25 \mathrm{mg} / \mathrm{ml}, 50 \mathrm{mg} / \mathrm{ml}$ and at 100 $\mathrm{mg} / \mathrm{ml}$ to group respectively. All the test samples were prepared in sterile water. In the study observations were made for the time taken to paralysis and death of individual worms. Time for paralysis was noted when no movement of any sort even after transfer to normal saline. Death was concluded when the worms lost their motility completely and failed to respond even after a touch with the needle followed by fading of their body colors ${ }^{26}$.

Due to the anatomical and physiological resemblances to the human intestinal round worm parasite, the assay was performed on adult earth worm, Pheretimaposthuma[27, 28]. The individual earth worms were placed in petridishes containing distilled water, three different concentrations of extracts and standard Albendazole. The time for the paralysis and death was noted. The earthworms in control group (group I) were alive up to $24 \mathrm{hrs}$ of the experiment $[29,30]$. Mean values of paralysis time and death time of Pheretimaposthumaearthworms and were calculated separately and tabulated.

\subsection{Statistical analysis}

The statistical analysis was carried out by one way analysis of variance (ANOVA). All the data were presented as Mean \pm SEM. 


\subsection{Phytochemical study of test samples}

\section{Results}

The qualitative analysis of test samples of seed showed the presence of different secondary metabolites. The results of phytochemical screening of seeds are shown in the table No-1.

Table No-1: Phytochemical study of test samples for phytochemical constituents

\begin{tabular}{|c|l|l|l|}
\hline SI NO & \multicolumn{1}{|c|}{ EXTRACT } & YIELD & CONSTITUENTS \\
\hline 1. & Ethanol & $\begin{array}{l}\text { Carbohydrates, Alkaloids, Steroids, Triterpenoids, } \\
\text { Tannins, Glycosides, Flavonoides, Saponins. }\end{array}$ \\
\hline 2. & Ethyl acetate & & Steroids, Triterpenoids, Flavonoides, Saponins. \\
\hline 3. & Aqueous & & $\begin{array}{l}\text { Carbohydrates, Alkaloids, Steroides, Triterpenoides, } \\
\text { Glycosides, Flavonoides, Saponins. }\end{array}$ \\
\hline
\end{tabular}

\subsection{Anthelmintic Activity of various extract of Artocarpusheterophyllus}

Artocarpusheterophyllus seed extract has shown good anthelmintic activity. The results are displaced in table-2.

Table-2 showing anthelmintic activity of various extracts of Artocarpusheterophyllus

\begin{tabular}{|l|l|l|l|l|}
\hline GROUP & TREATMENT & $\begin{array}{l}\text { CONCENTRATION } \\
(\mathbf{m g} / \mathbf{m l})\end{array}$ & $\begin{array}{l}\text { TIME } \\
\text { FOR PARALYSIS }\end{array}$ & $\begin{array}{l}\text { TIME } \\
\text { FOR DEATH }\end{array}$ \\
\hline GP-1 & Control & $5 \% \mathrm{Normal}$ saline & - & - \\
\hline GP-2 & Albendazole & $25 \mathrm{mg}$ & $19.83 \pm 0.95$ & $26.83 \pm 0.93$ \\
& (standard) & $50 \mathrm{mg}$ & $15.50 \pm 0.89$ & $20.83 \pm 0.95$ \\
& & $100 \mathrm{mg}$ & $09.17 \pm 0.70$ & $14.17 \pm 0.95$ \\
\hline GP-3 & Ethanol extract & $25 \mathrm{mg}$ & $95.33 \pm 0.88$ & $117.50 \pm 0.99$ \\
& (test sample) & $50 \mathrm{mg}$ & $64.50 \pm 0.92$ & $86.67 \pm 0.84$ \\
& & $100 \mathrm{mg}$ & $120.67 \pm 0.67$ & $66.17 \pm 0.87$ \\
\hline GP-4 & Aqueous & $25 \mathrm{mg}$ & $78.50 \pm 0.99$ & $147.17 \pm 0.93$ \\
& (test sample) & $50 \mathrm{mg}$ & $64.67 \pm 0.88$ & $106.50 \pm 0.99$ \\
& & $100 \mathrm{mg}$ & $82.67 \pm 0.88$ & $117.50 \pm 0.90$ \\
\hline GP-5 & Ethyl acetate & $25 \mathrm{mg}$ & $57.17 \pm 0.95$ & $109.50 \pm 0.99$ \\
& (test sample) & $50 \mathrm{mg}$ & $46.67 \pm 0.67$ & $92.50 \pm 0.85$ \\
& & $100 \mathrm{mg}$ & $66.17 \pm 0.87$ \\
\hline
\end{tabular}

Histogramshowing the effect of seed extracts of Artocarpusheterophyllus on the worms at different concentration.

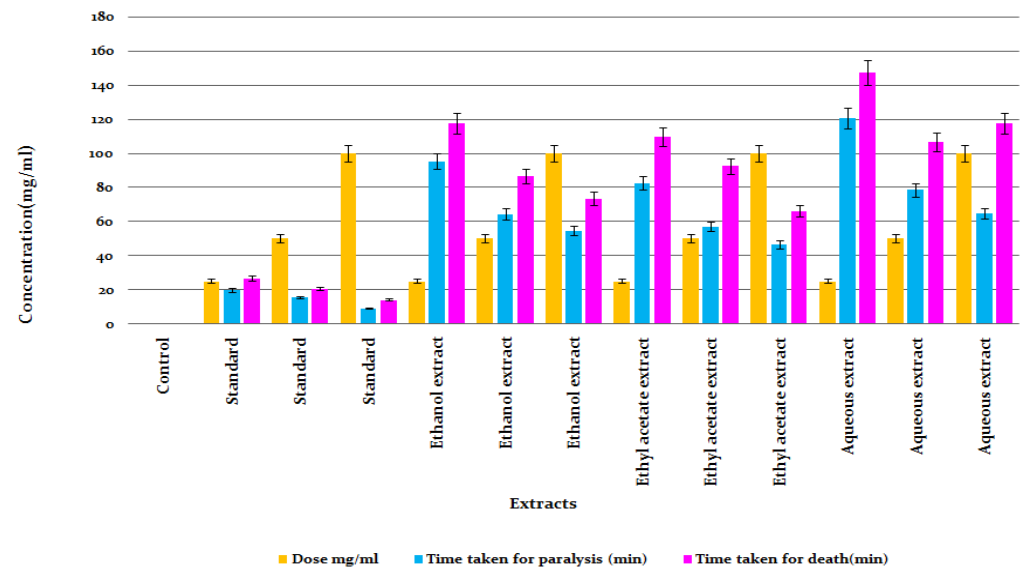

Fig 1-showing the effect of seed extracts of Artocarpusheterophyllus on the worms at different concentration. 


\section{Discussion}

In the present study the test samples of seed extracts of plant Artocarpusheterophyllusbelongs to the family Moraceae were tested for anthelmintic activity. The anthelmintic activity has also been reported for extracts of many plants like, Artocarpusaltillis[31], Artocarpuslakoocha[32],Streblusasper[33], Morusalba[34 35], Ficusracemosa[36], FicusCarica[37], Morusaustralis[38], Ficusriligiosa[39], Ficusbengalensis ,Ficusglomerata, Morusindica, Moruslaevigata[40],Ficuselastic[41], Ficushispida[42] have the same familyof Moraceae have been reported with significant anthelmintic activity. However, anthelmintic activity has not been reported for the metabolites of the plant seeds of Artocarpusheterophyllus. Hence, in the present study anthelmintic activity for the seed extract of Artocarpusheterophyllushas been evaluated.

In the present study anthelmintic activity was evaluated by Ajaiyeobaet.al method. The ethyl acetate ethanol and aqueous extracts of seed exhibited significant anthelminthic activity in comparison with control.

Amongst all the extracts, Ethyl acetate extract showed better activity. It indicates that certain non-polar constituents are responsible for the activity. This anthelmintic activity is mainly due to the presence of secondary metabolites- Alkaloids, flavonoids and Triterpenoides. There are several reports on Alkaloids and flavonoids exhibiting anthelmintic activity [43, 44].

\section{Conclusion}

The ethyl acetate, ethanol and aqueous extracts exhibited significant anthelmintic activity. The test samples can be evaluated further for other pharmacological properties which may be useful in designing of new drugs of anthelminthic activity.

\section{Reference}

[1]. Ravindra GM, Shailaja GM, Anita AM. In vitro Screening of Cleome viscosa. Extract for anthelmintic activity. Pharmaceut.Bio.10: 2007; 766-768.

[2]. $\quad$ Nakatani, M., Huang, R.C., Okamura, H., Iwagawa, T., Tadera, K., 1998. Degrade

[3]. limonoids from Meliaazedarach. Phytochemistry 49, 1773-1776.Pomilio, A.B, Vitale, A.A, 1988.Métodos.

[4]. Mendhe BB. Nema U, Gupta P. and Gandhare BR, 2010. "Evaluation of Anthelmintic activity of leaf extracts of ButeaMonosperma" International Journal of Pharmaceutical Sciences and Research 1(3): p. 69-72.

[5]. Qureshi S. Md., Patel J., Giri C. I., Hasan S, Shaik M. and HamedMd,. "In vitro anthelmintic activity of root extract of TrapabispiniosaRoxb. Against Pheretimaposthuma and Ascardiagilli. Study of anthelmintic activity" International Journal ofPharma Science and Research 1 (9), 2010, p. 353-356.

[6]. Pessoa LM, Morias SM, Bevilaqua CM, Luciano JH. Anthelmintic activity of essential oil of Ocimumgratissimum Linn.And euginol against Haemonchuscontortus. Vet Parasitol2002; 109:59-63.

[7]. Introduction to medicinal plants history and context.

[8]. Sunil koshy, PrinkeshFanasia, Prima freedad'souza, Gopikrishna. Evaluation of Diuretic activity of Hydro alcoholic extracts of Artocarpusheterophyllus leaves in rats. Journal of basic and applied Biology; 6;2012, 97101.http://en.wikipedia.org/wiki/A.heterophyllus

[9]. Om prakash, Rajesh Kumar, Anuragmishra, Rajiv gupta. Artocarpusheterophyllus (jack fruit): a review. Journal of Pharmacognosy rev, 3, 2009, 353-358.

[10]. Jensen and William B. The origin of the soxhlet extractor. Journal of Chemical Education,84, 2007,1913-1914.

[11]. Bandar HA, Rammal H, Hachem A, Saad Z and Badran B. Techniques for the extraction of bioactive compounds from Lebanese urticadioica. American Journal of Phytomedicine and Clinical Therapeutics,6, 2013, 507-513.

[12]. R.D. Gibbs, “Chemotaxonomy of Flowering Plants", McGill Queen's University press, Montreal and London, $1974 ; 1$.

[13]. O.O. Aiyelaagbe and M.PaulOsamudiamen, "Phytochemical Screening for Active Compounds in MangiferaindicaLeaves from Ibadan", Oyo State, 2(1),2009,11-13.

[14]. B.D.H. El-Tawil, "Chemical constituents of indigenous plants used in Native Medicine of Saudi Arabia, II" Arab Gulf J SciResA; 1(12), 1983,395 -410.

[15]. R. Chandrashekar and S.N. Rao, "Phytochemical analysis of ethanolic extract of leaves of leucasindica(eelli)" Int J Pharm Bio Sci.4 (1), 2013, $33-38$.

[16]. K.R. Brain and T.D. Turner, "The practical evaluation of phytochemicals", Wright Science Technical: Bristol 1975.

[17]. P. Tiwari, B. Kumar, M. Kaur, G. Kaur, H. Kaur, " Phytochemical screening and extraction: A review", InternationalePharmaceuticaSciencia, 1(1),2011,98-106,

[18]. Veena Sharma, AasthaAgarwal, UrmilaChaudhary, Manu Singh, "Phytochemical investigation of various extracts of leaves and stems of AchyranthesasperaLinn." International Journal of Pharmacy and Pharmaceutical Sciences, 2013; 5: suppl.

[19]. D. SaiKoteswarSarma and A. Venkata Suresh Babu, "Pharmacognostic and phytochemical studies of ThespesiapopulneaLinn," J. Chem.Pharm. Res,3(4), 2011, 237-244, 2011.

[20]. SaxenaMamta and SaxenaJyoti, "Phytochemical screening of AcorusCalamusand Lantana Camara", International research Journal of Pharmacy,3(5),2012, 323-326.

[21]. A. Odebiyi and A.E. Sofowora, "Phytochemical screening of Nigeria medicinal plant", part III Lioydia, l (4), 1978, 234-246.

[22]. SeemaFirdouse, ParwezAlam, "Phytochemical investigation of extract of Amorphophalluscampanulatustubers", International Journal of Phytomedicine, 2011; 3: 32-35.

[23]. A. Sofowora, "Medicinal plants and traditional medicine in Africa", John Wiley, Chichester, 1982; 179.

[24]. Singh Priyam, ShrivastavaRajni, Sharma Manic, Singh M. Invivo Antitumor, Antioxidant activities and Toxicity profile of Ethyl Acetate Crude Leaf Extract of Parkinsonia aculeate L. (Fabaceae) on B16F10 Melanoma. International Research Journal of Pharmacy, 4(10),2013;p.89-93.

[25]. Ghosh MN. Fundamentals of experimental Pharmacology, Toxicity studies.Scientific Book agency, Calcutta,2, 1984,44-52. 
[26]. ArasanElayaraja, M Vijayalakshmi and DevalaraoGarikapati. Anthelmintic screening of various crude extracts of phyllanthus simplex Retz. Research journal of pharmaceutical, Biological and chemical sciences, 1(4),2010,425-428.

[27]. Chaterjee, K.D. Parasitology, protozoology and Helminthology. $6^{\text {th }}$ ed.Guha ray sreeSaraswathi press Ltd. Calcutta, India.

[28]. Vidyarthi, R.D. A text book of Zoology.14 $4^{\text {th }}$ ed. S. Chand and co. New Delhi, India.

[29]. SeemaNakhare, Garag SC. Anthelmintic activity of Artemisia Pollens wall. Ancient Science of life,3,1991,185-186.

[30]. Hunt T.K, Ehrlich H.P, Gracia JA, Dunphy J.E. Effects of vitamin A on reversing the inhibitory effect of cortisone on healing of open wounds in animals and man. Ann. Surg, 170(2), 1969, 633-641.

[31]. Somashekar M, Naira, Nayeem, Basavarajsonnad. A review on family Moraceae with a focus on Artocarpusspecies.World journal of pharmacy and pharmaceutical sciences, 2013; 2614-2621.

[32]. Saowakon.Naruwan.Fasciolagigantica. Anthelmintic effects of aqueous effects of Artocarpuslakoocha experimental parasitology, 2009; 289-298

[33]. Chaterjee RK. Macrofilaricidal activity of stem bark of streblusasperand its major activeconstituents. Drug Dev Res,(26), 1992, 6778.

[34]. Adithya RSJ, Ramesh CK,RiazM,PrabhakarBJ.Anthelmintic and antimicrobial activities in some species of mulberry.International journal of pharm sciences,(5),2013,335-338.

[35]. Bandna Devi, Neha Sharma, Dinesh Kumar, Kamal jeet. Morus Albalinn.Aphytopharmocological review. International journal of pharm sciences, (5), 2013, 14-18.

[36]. Chandrashekhar CH, Latha KP, Vagdevi HM, Vaidya VP. Anthelmintic activity of the crude extracts of Ficusracemosa. International journal green pharm,(2), 2008,100-103.

[37]. A. De Amorin, H.R.Borba, J.P.P, M.A.Kaplan.Anthelmintic activity of the Latex of Ficusspecies. Journal of Ethnopharmacology, (64), 1999, 225-258.

[38]. Kumar VR, Chauhan Mulberry. Journal of medicional plant research,(28), 2008, 271-278.

[39]. AmandeepKaur, A.C.Rana, VineeaTiwari, Ramica Sharma. Review on ethanomedicinal and pharmacological properties of Ficusreligiosa. Journal of applied pharmaceutical sciences, 1(8), 2011, 6-11.

[40]. Tahiraazizmughal, Samiaarshad and Sana mahboob. Evaluation of Anthelmintic activity of some members of family Moraceae.Journal of medicinal plant research,7(30), 2013, 2275-2279.

[41]. B.N.Vedhahari, P.Saravanakumar, D. Ramya Devi. Comparitive in-vitro Anthelmintic activity of the Latex of Ficusreligiosa, Ficus elastic and Ficusbengalensis.Journal of phytology, 2011;26-30.

[42]. Sousa, Barborafilho, MeloDiniz, Batista et.al. Anthelmintic activity of native America plants: a review. Rev.bras.plantas med, 2013; 15.

[43]. Abhishek B, Anita Thakur. Anthelmintic activity of cynodondactylon.Journal of pharmacognacy and photochemistry,(1), 2012, 1-

[44]. NayakSarojini, Chakraborti Chandra kanti, JaiswalPriyanka, Sahushakumari. Correlation between the phytochemical constituents and Anthelmintic activity of Lawsoniaintermis leaf extracts. IJRAP,3(4), 2012, 559-562. 